\title{
Functional Domains in Dorsal Striatum of the Nonhuman Primate Are Defined by the Dynamic Behavior of Dopamine
}

\author{
Stephanie J. Cragg, Christopher J. Hille, and Susan A. Greenfield \\ University Department of Pharmacology, Oxford OX1 3QT, United Kingdom
}

The dorsal striatum comprises a continuum of distinct functional domains, limbic, associative, and sensorimotor. In the primate it exclusively subdivides further into two nuclei, the putamen and caudate. Dopamine (DA) transmission is differentially affected between these nuclei in neurodegenerative diseases such as Parkinson's and by psychostimulants such as cocaine. Because rodent systems can offer only limited insight into DA systems of the human brain, a fuller appreciation of DA transmission and its role in dysfunction requires direct study in primates.

DA behavior was explored in the major functional domains of the caudate nucleus and compared with the putamen, using fast-scan cyclic voltammetry in striatal sections from the marmoset (Callithrix jacchus). There was domain-specific variation in extracellular DA transients [i.e., concentration ([DA] $]_{\circ}$ released by a single stimulus and the rate maximum of DA uptake, $V_{\text {max }}$. Across nuclei, functional rather than anatomical regions were differentiated by these dynamics. The largest,

A distinction between putamen (Put) and caudate $(\mathrm{Cd})$ nuclei, divided by the internal capsule, is a hallmark of the primate dorsal striatum. Interestingly, uneven patterns of mesostriatal dopamine (DA) cell loss render the most dorsolateral (dl) regions of the putamen most susceptible, whereas the caudate nucleus remains less affected, in both idiopathic Parkinson's disease (PD) and 1-methyl-4-phenyl-1,2,3,6-tetrahydropyridine (MPTP) parkinsonism in primate models (Hornykiewicz, 1966; Schoemaker et al., 1985; Elsworth et al., 1987; Kish et al., 1988; Maloteaux et al., 1988; Seeman and Niznik, 1990; Kaufman and Madras, 1991; Moratalla et al., 1992; Antonini et al., 1995). However, this anatomical subdivision is only one way of analyzing the primate striatum. In particular, corticostriatal connectivity defines three distinct but interrelated "functional domains" that span the caudate and putamen: ventromedial (vm)/limbic-, central/associative-, and dorsolateral/motor-associated (Kunzle, 1975, 1977; Selemon and Goldman-Rakic, 1985; Haber and McFarland, 1999). Such topographic segregation is maintained throughout the primate basal ganglia, inter alia, thalamostriatal (Gimenez-

Received Feb. 27, 2002; revised April 9, 2002; accepted April 11, 2002.

This work was supported by an E. P. Abraham Research Fellowship (Keble College, Oxford, UK), by Novartis Pharma (S.J.C.), and by Synaptica Ltd. (C.J.H.). S.J.C. is a Beit Memorial Research Fellow. We thank Dr. S. Judge, Dr. A. Whatham, and P. W. Tynan for their contributions.

Correspondence should be addressed to Stephanie J. Cragg, University Department of Pharmacology, Oxford OX1 3QT, UK. E-mail: stephanie.cragg@ pharm.ox.ac.uk.

Dr. Hille's present address: Department of Migraine and Stroke, Neurology Centre of Excellence for Drug Discovery, New Frontiers Science Park, Harlow, Essex CM19 5AW, UK.

Copyright (C) 2002 Society for Neuroscience $0270-6474 / 02 / 225705-08 \$ 15.00 / 0$ fastest DA transients were at motor-associated loci. Evoked $[D A]_{0}$ at physiological frequencies was differently frequencysensitive between functional domains but not between anatomical nuclei. In contrast, presynaptic depression was not an index of regional differentiation, recovering with similar kinetics at all loci.

Within a given functional domain of dorsal striatum, the dynamics of DA release and uptake are similar for the putamen and the caudate nucleus. Conversely, distinct functional domains are defined by these DA dynamics, in a manner more marked in primates than in rodents. These data from the primate brain highlight differences in DA availability that may be central to DA function and dysfunction in the human.

Key words: caudate; putamen; Parkinson's disease; basal ganglia; dopamine transporter; dopamine uptake; marmoset; voltammetry; corticostriatal; nigrostriatal; striatonigral; mesostriatal; cocaine; synaptic depression; primate; ventral striatum

Amaya et al., 1995; McFarland and Haber, 2000), amygdalostriatal (Russchen et al., 1985), striatopallidal (Hazrati and Parent, 1992), and striatonigral projections (Lynd-Balta and Haber, 1994a; Haber et al., 2000) and even somatotropic organization (Crutcher and DeLong, 1984; Alexander and DeLong, 1985). Furthermore, different functional domains receive inputs from different mesostriatal DA neurons (Szabo, 1980; Parent et al., 1983; Smith and Parent, 1986; Lynd-Balta and Haber, 1994b; Haber et al., 2000). Consequently, to understand striatal DA function and, in turn, dysfunction, it is essential to explore these features in functionally rather than anatomically (caudate/putamen) segregated domains.

We have shown previously that within the putamen of a nonhuman primate there are significant differences in DA behavior that parallel the functional organization (Cragg et al., 2000). Yet this same repertoire of region-specific differences is not as apparent in the dorsal striata of rodents (Cragg et al., 2000). In this study, using fast-scan cyclic voltammetry, we have now determined the dynamic behavior of DA in the primate caudate nucleus and compared these findings with those we described previously for the putamen. In this manner, we have determined in real time the dynamics of extracellular DA in limbic- through to motor-associated functional domains throughout the dorsal striatum. We have profiled DA dynamics by single-pulse availability, uptake rate maximum $\left(V_{\max }\right)$, frequency sensitivity, and presynaptic depression. We address the hypotheses that there are differences in DA dynamics within the caudate nucleus that reflect functional subdivision, akin to that observed in the putamen, rather than the anatomical segregation of the caudate versus 
Figure 1. Regional variation in single pulseevoked $[\mathrm{DA}]_{\mathrm{o}}$ between domains of the dorsal striatum. $a, c$, Mean $[\mathrm{DA}]_{\mathrm{o}}$ versus time evoked by a single pulse (arrows) at varying $\mathrm{vm}$ to $\mathrm{dl}$ coordinates in the $\mathrm{Cd}$ and Put at two ranges of AP coordinates of striatum: rostral-central, $11.9-10.5 \mathrm{~mm}(a)$ and central-postcommissural, $10.25-8.5 \mathrm{~mm}(c)$. Inset, Cyclic voltammogram indicating oxidation and reduction peaks for DA. Typical $\mathrm{vm}-\mathrm{dl}$ recording sites are illustrated by the circles in $b$, a schematic illustration of a coronal striatal section, $10.5 \mathrm{~mm}$. IC, Internal capsule; Dors, dorsal; Lat, lateral. At both coordinate ranges in $a$ and $c$, there is significant regional variation in $[\mathrm{DA}]_{\mathrm{o}}$ along this ventromedial-dorsolateral axis in both the caudate (one-way ANOVA; $p<0.001$ ) and the putamen $(p<0.001)$. Post hoc $t$ tests: ${ }^{*} p<0.05 ;{ }^{* *} p<0.01 ; * * * p<0.001$ versus ventromedial; $n=4-25$. In the putamen, there is lateral variation between each of the three territories $\left({ }^{\dagger} p<0.05,{ }^{\dagger \dagger} p<0.001\right.$ vs central). $d$, Geographic representation of overall mean peak $[\mathrm{DA}]_{\mathrm{o}}$ evoked from the caudate and the putamen along vm- $\mathrm{dl}$ axes. $* * * p<0.001$ versus ventromedial; †† $p<$
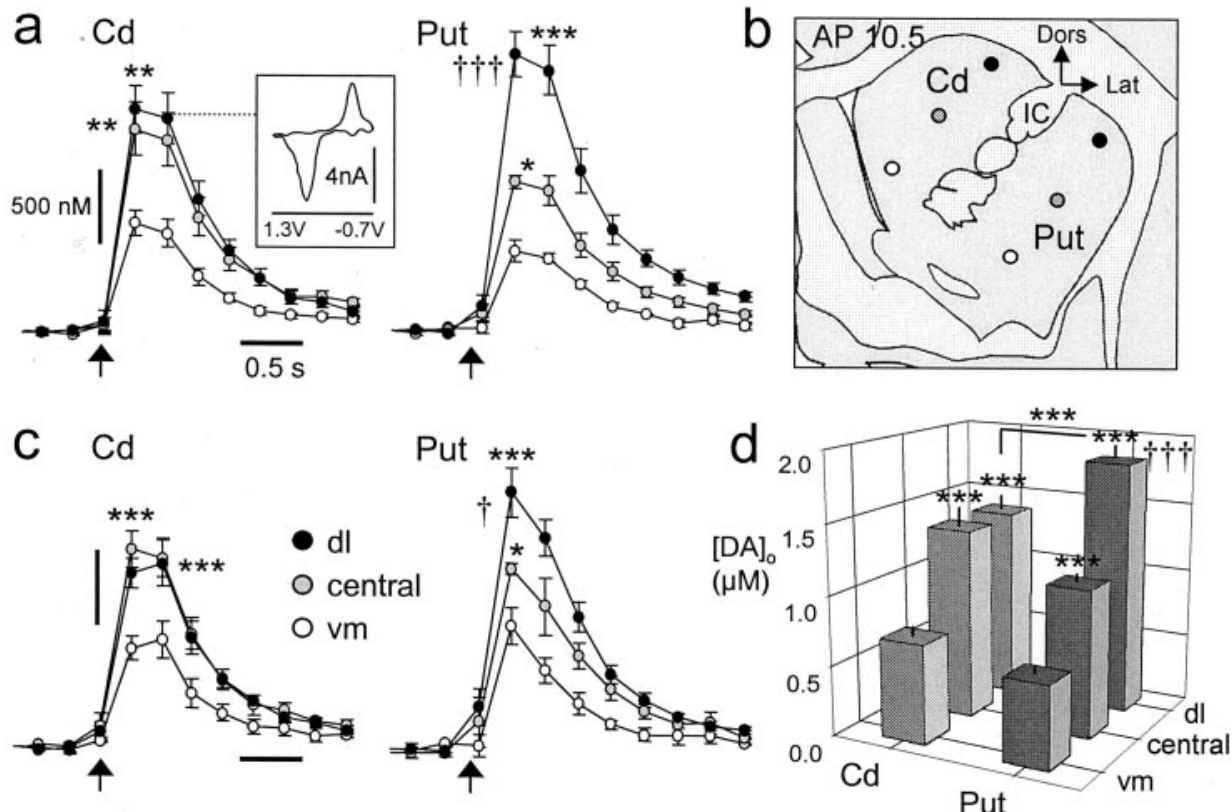

0.001 versus central; post hoc $t$ tests. Only at the dorsolateral coordinate is $[\mathrm{DA}]_{\mathrm{o}}$ significantly greater in the putamen than in the caudate nuclei $(* * * p<$ $0.001 ; n=11-41)$. [DA] $]_{\mathrm{o}}$ follows the following hierarchy: dorsolateral putamen $>$ dorsolateral caudate $\approx$ central caudate $\approx$ central putamen $>$ ventromedial caudate $=$ ventromedial putamen. All data are means \pm SEM.

the putamen or other structural organization of the nuclei. In addition, we discuss how these data provide additional support for the hypothesis (Wu et al., 2001) that it is such dynamics that underlie the paradoxical, documented preferential action of cocaine in the limbic- rather than motor-associated striatum (Carboni et al., 1989; Cass et al., 1992; Kuczenski and Segal, 1992; Bradberry et al., 2000). These data illustrate the functionassociated repertoire of DA dynamics in the striatum of a nonhuman primate of central relevance to basal ganglia function in health and disease.

\section{MATERIALS AND METHODS}

Brain slice preparation. Male marmosets (1-2 years) from an established colony were killed with an overdose of pentobarbitone (i.p.). Striatal slices $(400 \mu \mathrm{m})$ were prepared in ice-cold, HEPES-buffered physiological saline saturated with $95 \% \mathrm{O}_{2}$ and $5 \% \mathrm{CO}_{2}$, as described previously (Rice et al., 1997; Cragg et al., 2000) using a Vibratome (Lancer Series 1000; Lancer, St. Louis, MO). Striatal coordinates were midcommissural to rostral [anteroposterior (AP), 8.5-11.5 mm] (Stephan et al., 1980). All recordings were made at $32^{\circ} \mathrm{C}$ in bicarbonate-buffered artificial CSF (aCSF; 95\% $\mathrm{O}_{2}$ and 5\% $\mathrm{CO}_{2}$ ) as described previously (Cragg et al., 2000).

Anatomical definitions. By dorsal striatum, we mean the striatum excluding the nucleus accumbens. According to corticostriatal connectivity (Selemon and Goldman-Rakic, 1985; Haber and McFarland, 1999), three major functional domains of the striatum can be delineated along a ventromedial to dorsolateral axis: ventromedial, central, and dorsolateral. Each domain is associated, respectively, with one of the following functions (and distinct frontal inputs): limbic (orbital and medial prefrontal cortex), cognitive/associative (dorsolateral prefrontal cortex), and sensorimotor (premotor and motor cortex). In both the caudate and the putamen, we defined three recording sites for comparison along the ventromedial-dorsolateral axis: vm, central (or mid), and dl, respectively (Fig. 1b). These regions correspond approximately to the three functionally defined territories, with the exception of the caudate nucleus, in which both the central and dorsolateral regions sampled are predominantly cognitive-associated, central striatum. Therefore, note that the dorsolateral loci in the caudate sampled in this study, unlike dorsolateral loci in putamen, do not constitute a component of the dorsolateral striatum (DLS) as defined by Haber et al. (2000).
Voltammetry and microelectrodes. [DA $]_{\mathrm{o}}$ was measured using fast-scan cyclic voltammetry at a $6 \mu \mathrm{m}$ carbon-fiber microelectrode beveled to a point (tip length, $\sim 30 \mu \mathrm{m}$; MPB Electrodes, London, UK) using a Millar Voltammeter (PD Systems, West Moseley, UK) as described previously (Cragg and Greenfield, 1997; Cragg et al., 2000). The scan rate was 800 $\mathrm{V} / \mathrm{sec}$, from -0.7 to $1.3 \mathrm{~V}$ to $-0.7 \mathrm{~V}$ versus $\mathrm{Ag} / \mathrm{AgCl}$, and the sampling frequency was $4-8 \mathrm{~Hz}$. Illustrated voltammograms are faradic currents obtained by subtraction of background current. Identification of the released substance as DA was confirmed by comparison in situ and in DA calibration of oxidation and reduction potentials $(+540$ and $-180 \mathrm{mV}$ vs $\mathrm{Ag} / \mathrm{AgCl}$, respectively). Contributions from the monoamine oxidase (MAO)-metabolite DOPAC or norepinephrine (NE) were determined as minimal from experiments including MAO inhibition (pargyline) and $\mathrm{NE}$ uptake inhibition (desipramine). Electrodes were calibrated in 1-2 $\mu \mathrm{M}$ DA in aCSF. Sensitivity to DA is linear at these concentrations and typically $2-7 \mathrm{nA} / \mu \mathrm{M}$. The minimum detection limit for $[\mathrm{DA}]_{\mathrm{o}}(\sim 2 \times$ currents for noise) was roughly $20-40 \mathrm{nM}$.

Electrical stimulation. Electrical stimulation was at local, surface bipolar electrodes $(50 \mu \mathrm{m}$ diameter), as described previously (Cragg et al., 2000). Stimulus pulses ( $0.1 \mathrm{msec}$ pulse width, half-maximal at $10 \mathrm{~V})$ were applied in one of three paradigms: singly; in trains at $1-20 \mathrm{~Hz}$ for $3 \mathrm{sec}$; or in pairs with interstimulus intervals ranging from $50 \mathrm{msec}$ to $40 \mathrm{sec}$ (and interpair intervals of $5 \mathrm{~min}$ ). Evoked release was TTX-sensitive and $\mathrm{Ca}^{2+}$-dependent (data not illustrated).

Analysis of data and dopamine kinetics. Voltammetric data were acquired and analyzed on a personal computer running the Strathclyde Whole Cell Program (Dr. J. Dempster, University of Strathclyde, Strathclyde, UK). Data simulations for analysis of Michaelis-Menten kinetics used software provided by Dr. R. M. Wightman (University of North Carolina, Chapel Hill, NC) to fit each experimental data curve (concentration vs time) with theoretical curves. The kinetic analysis is based on the assumption that DA released into the extracellular space after a single pulse appears as an instantaneous concentration increase, $[D A]_{p}$, followed by a rapid decline that is predominantly attributable to transporter-mediated uptake (Giros et al., 1996), operating with MichaelisMenten kinetics. Concentration-time $(t)$ profiles can be described by the following equation: $d[\mathrm{DA}] / d t=[\mathrm{DA}]_{\mathrm{p}}-V_{\max } /\left\{\left[K_{\mathrm{m}} /(\mathrm{DA})\right]+1\right\}$, where $K_{\mathrm{m}}$ is the affinity constant of the dopamine transporter (DAT) and $V_{\max }$ is the maximum velocity of uptake. This method of analysis has been described in detail previously (Wightman and Zimmerman, 1990; Kawagoe et al., 1992; Jones et al., 1995) and incorporates a factor $d$ that introduces a delay to compensate for electrode response time attributable to surface coatings or other interactions at uncoated electrodes. In 
the present studies, $d(140-220 \mathrm{~nm})$ was comparable with that reported previously (Cragg et al., 2000). $K_{\mathrm{m}}$ was set at a constant value of $210 \mathrm{nM}$ (Ross, 1991; for review, see Cragg et al., 2000). For each accepted simulation, $R^{2}$ was $>0.9$. In cases in which small changes in variable parameter values could sometimes give equal degrees of fit (equivalent $R^{2}$ ), both sets were included for analysis ( $n=$ number of simulations). Data simulations were undertaken blind with respect to recording site. Linear regressions, Pearson correlations, and slope comparisons used GraphPad software (GraphPad Software Inc., San Diego, CA).

Paired-pulse data were used to determine time constants for recovery of release at a given site using a double exponential curve fit (Kennedy et al., 1992) of the form $y=y_{0}+a\left(1-\exp ^{-\mathrm{b} x}\right)+a\left(1-\exp ^{-\mathrm{c} x}\right)$, where $x$ is time and $a, b$, and $c$ are variables. We include a $y$-intercept term, $y_{0}$, because this relationship may not necessarily approach zero at time 0 in a simple manner (our unpublished observation). We constrained $a$ and $y_{\max }$ to a relationship in which $y_{\max }=y_{0}+2 \times a=1$. Time constants were $[\ln 2] / b$ and $[\ln 2] / c$.

Data are means \pm SEM and the sample size is the number of recording sites, unless otherwise stated. Some data from the putamen have been published in part previously (Cragg et al., 2000); we have included expanded data about the putamen, where appropriate, from sets that match those for the caudate to make comparisons with the caudate. The number of animals in each experiment is 3-12. Comparisons for differences in means were assessed by one- or two-way ANOVA and post hoc multiple comparison $t$ tests (Newman-Keuls). In pulse train experiments, "net" or "steady-state" refers to [DA] at a period during the stimulation during which $[\mathrm{DA}]_{\mathrm{o}}$ approaches an apparent steady state (2-3 $\mathrm{sec})$. Note that the steady state may be a complex state and is not necessarily seen at high frequencies.

Solutions. All drugs and solutions were obtained from Sigma (Poole, UK).

\section{RESULTS}

\section{Single-pulse evoked [DA]。 within and between striatal domains}

A single, electrical stimulus pulse in marmoset striatum evoked the rapid release and removal of the electroactive substance, DA. The substance was identified as DA by a characteristic voltammogram with peak potentials for oxidation $(\sim 500 \mathrm{mV})$ and reduction currents $(\sim-200 \mathrm{mV}$ vs $\mathrm{Ag} / \mathrm{AgCl})$ (Fig. $1 a$, inset) that are identical for exogenously applied DA and DA signals obtained previously, including in marmoset putamen (Cragg et al., 2000). The metabolite DOPAC did not contribute significantly to evoked signals in the putamen (Cragg et al., 2000) or in the caudate nucleus: inhibition of monoamine oxidases $\mathrm{A}$ and $\mathrm{B}$ for up to $5 \mathrm{hr}$ (pargyline, $20 \mu \mathrm{M}$ ), had no effect on the magnitude of the signal observed ( $n=4$; data not shown).

There was significant regional variation in evoked $[\mathrm{DA}]_{\mathrm{o}}$ within both the caudate and the putamen attributable to vm-dl coordinates at both central-rostral locations (Fig. 1a,b) (one-way ANOVAs; $p<0.001$; caudate, $n=9-16$; putamen, $n=7-25)$ and central-postcommissural locations (Fig. 1c) (one-way ANOVAs; $p<0.001$; caudate, $n=6-12$; putamen, $n=4-15)$. Throughout the AP range of the striatum investigated, evoked $[\mathrm{DA}]_{\mathrm{o}}$ in dorsolateral positions was significantly greater than that released ventromedially, by more than twofold in the caudate and, most markedly, by threefold in the putamen. The more marked regional variation within the putamen than within the caudate was attributable to the most elevated $[\mathrm{DA}]_{\mathrm{o}}$ of all of those occurring in the dorsolateral putamen.

No significant effect of the AP coordinate was detected in either the caudate or the putamen (two-way ANOVAs). There was a trend in ventromedial putaminal regions toward higher evoked $[\mathrm{DA}]_{\mathrm{o}}$ more caudally. At these loci, the most medial coordinate of the putamen is more lateral than in rostral regions (Stephan et al., 1980). For all subsequent data analysis, AP data were pooled. Within the caudate nucleus, the mean evoked [DA] in central and dorsolateral regions was twice that seen in ventromedial areas (Fig. 1d) (193 $\pm 17 \%$ and $197 \pm 15 \%$ of ventromedial, respectively; $p<0.001 ; n=17-28)$. In contrast, within the putamen, there was significant variation between each of the three subregions measured, such that there was more than a threefold vm-dl variation in evoked [DA] (Fig. 1d) (dorsolateral $313 \pm 18 \%>$ central $181 \pm 8 \%$ of ventromedial; $p<0.001 ; n=$ 11-41).

A comparison of putamen versus caudate nuclei reveals that internucleus variation $(20-30 \%)$ is a far smaller source of variation than intranucleus variation $(300 \%)$. At similar vm-dl coordinates in the caudate and the putamen, $[\mathrm{DA}]_{\mathrm{o}}$ is similar in all but the most lateral regions: The only significant source of variation between the caudate and the putamen (two-way ANOVA; $p<$ $0.05)$ is at this dorsolateral coordinate, where the mean $[\mathrm{DA}]_{\mathrm{o}}$ in the putamen $(1.83 \pm 0.11 \mu \mathrm{M} ; n=41)$ exceeds that in the caudate by $33 \%(1.38 \pm 0.11 \mu \mathrm{M} ; p<0.001 ; n=28)$. This region-specific availability of DA parallels the segregation of the functional organization of the striatum, as delineated by corticostriatal topography.

\section{Dopamine uptake pharmacology}

Single-pulse evoked $[\mathrm{DA}]_{\mathrm{o}}$ and extracellular lifetime were unaltered by application of desipramine (300 nM), a competitive inhibitor of the NE transporter in the caudate nucleus (Fig. 2a) ( $n=7$; three applications) as well as the putamen (Cragg et al., 2000). In contrast, uptake by the DAT avidly regulated the extracellular concentration and lifetime of DA (Fig. $2 b$ ): during competitive inhibition of the DAT by GBR 12909 (500 nM), maximum $[\mathrm{DA}]_{\mathrm{o}}$, the clearance rate, and thus the extracellular lifetime of single-pulse evoked $[\mathrm{DA}]_{\mathrm{o}}$ throughout the caudate were significantly elevated (one-way ANOVA; $p<0.001 ; n=19$; four applications), as seen in the putamen previously (Cragg et al., 2000). Together, these data also verify that the substance measured is not NE but DA.

\section{Regional variation in $V_{\max }$ of dopamine uptake between striatal domains}

Each experimental observation of $[\mathrm{DA}]_{\mathrm{o}}$ versus time was modeled with simulations of Michaelis-Menten kinetics to evaluate the maximal uptake rate, $V_{\max }$, via the DAT, and the underlying release per pulse, $[\mathrm{DA}]_{\mathrm{p}}$ (Fig. $\left.2 c-f\right) . V_{\max }$ and $[\mathrm{DA}]_{\mathrm{p}}$ varied in a manner that was positively correlated (Fig. $2 d$ ) in the caudate (Pearson test; $p<0.001 ; r=0.50 ; n=67$ ) and in the putamen $(p<0.001 ; r=0.68 ; n=91)$.

Analysis of the distribution of the values of $[\mathrm{DA}]_{\mathrm{p}}$ and $V_{\max }$ within a vm-dl axis in each nuclei revealed significant effects of coordinate (Fig. 2e,f), as seen for $[\mathrm{DA}]_{\mathrm{o}}$ (Fig. $1 d$ ). [DA $]_{\mathrm{p}}$ varied significantly within the caudate (Fig. 2) $[1.67 \pm 0.10 \mu \mathrm{M}(\mathrm{vm})$ to $2.70 \pm 0.14 \mu \mathrm{M}(\mathrm{dl})$; one-way ANOVA; $p<0.001 ; n=16-30]$ and within the putamen (Fig. $2 e$ ) $[1.45 \pm 0.07 \mu \mathrm{M}(\mathrm{vm})$ to $3.35 \pm 0.16$ $\mu \mathrm{M}$ (dl); one-way ANOVA; $p<0.001 ; n=23-38]$. The central and dorsolateral caudate did not differ. The source of variation between the caudate and the putamen, when compared at paired coordinates (two-way ANOVA; $p<0.05$ ), was attributable to $25 \%$ greater $[\mathrm{DA}]_{\mathrm{p}}$ in the dorsolateral putamen than in the caudate. $[\mathrm{DA}]_{\mathrm{p}}$ in the dorsolateral putamen significantly exceeded release in all other regions.

$V_{\max }$ varied significantly within the caudate (Fig. $2 f$ ) $[3.51 \pm$ $0.15 \mu \mathrm{M} / \mathrm{sec}(\mathrm{vm})$ to $4.20 \pm 0.14 \mu \mathrm{M} / \mathrm{sec}(\mathrm{dl})$; one-way ANOVA; $p<0.001 ; n=16-30]$ and within the putamen (Fig. $2 f)[3.27 \pm$ $0.13 \mu \mathrm{M} / \mathrm{sec}(\mathrm{vm})$ to $4.94 \pm 0.13 \mu \mathrm{M} / \mathrm{sec}(\mathrm{dl})$; one-way ANOVA; 
Figure 2. DA uptake: pharmacology and $V_{\max } a, b$, Mean $[\mathrm{DA}]_{\mathrm{o}}$ versus time after a single pulse (arrow) in the caudate nucleus in the control (circles) and with an uptake transporter inhibitor for norepinephrine (a; desipramine, $300 \mathrm{nM}$; triangles) or DA (b; GBR 12909; $500 \mathrm{nM}$; squares). a, Desipramine had no effect on the peak [DA] or the removal rate $(n=7) . b$, GBR 12909 slowed the rate of removal and significantly enhanced $[\mathrm{DA}]_{\mathrm{o}}(n=19 ; * * p<$ 0.001). $c$, Data points of a typical observation in the central caudate (Mid Cd) after a single pulse (arrow). Superimposed is a simulated data curve that describes the $[\mathrm{DA}]_{\mathrm{o}}$ detected after release and uptake with Michaelis-Menten kinetics. In this example, $[\mathrm{DA}]_{\mathrm{p}}=2.15 \mu \mathrm{M}, V_{\max }=3.1$ $\mu \mathrm{M} / \mathrm{sec}, R^{2}=0.99, K_{\mathrm{m}}=210 \mathrm{nM}$, and $d=$ $180 \mathrm{~nm} . d, V_{\max }$ versus $[\mathrm{DA}]_{\mathrm{p}}$ from all simulations in the caudate (triangles; $n=$ 67) and the putamen (circles; $n=91$ ). Positive correlations (dotted lines) within the putamen $(r=0.68)$ and the caudate $(r=0.5)$ are significantly different from zero $(p<0.001)$. The mean $[\mathrm{DA}]_{\mathrm{p}}(e$; $* * *)$ and mean $V_{\max }$ within the caudate $(f$; bars) compared with the putamen (dashed and/or dotted lines; means \pm SEM) across
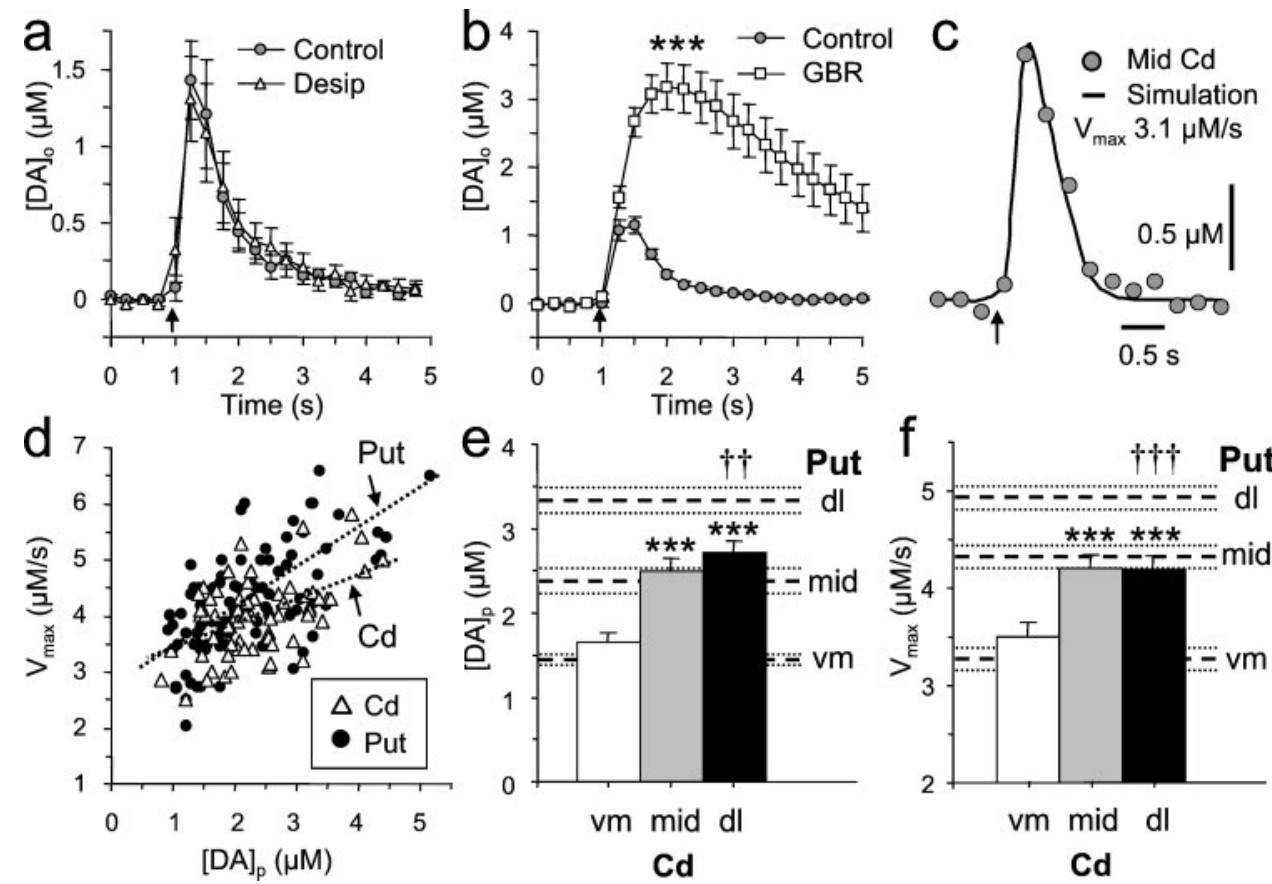

$\mathrm{vm}-\mathrm{dl}$ axes are shown. $[\mathrm{DA}]_{\mathrm{p}}$ and $V_{\max }$ increase significantly with an increasing dorsolateral coordinate in both nuclei (one-way ANOVAs; $p<0.001$; post hoc $t$ tests; ${ }^{* * *} p<0.001$ vs ventromedial) but only in the putamen is there a lateral variation between each of the three territories (Cragg et al., 2000) Only at the dorsolateral coordinate are either $[\mathrm{DA}]_{\mathrm{p}}$ or $V_{\max }$ significantly greater in the putamen than in the caudate $\left({ }^{\dagger \dagger} p<0.01 ;{ }^{\dagger \dagger} p<0.001 ; n=16-38\right)$. All data are means \pm SEM.

$p<0.001 ; n=23-38]$. The central and dorsolateral caudate did not differ. The source of variation between the caudate and the putamen, when compared at paired coordinates (two-way ANOVA; $p<0.05$ ), was attributable to $\sim 20 \%$ greater $V_{\max }$ in the putamen than in the caudate at dorsolateral regions. Indeed, the highest $V_{\max }$ observed was in the dorsolateral putamen, where $V_{\max }$ was significantly greater than in all other regions.

It should be noted that the values of $[\mathrm{DA}]_{\mathrm{p}}$ and $V_{\max }$ obtained using this approach were validated by an alternative means of estimating $V_{\max }$ (Cragg et al., 2000). After an intense stimulation (e.g., $100 \mathrm{~Hz}, 0.5 \mathrm{sec}$ train) that generates sufficiently high [DA] $\left(\gg K_{\mathrm{m}}\right.$ of the DAT), the clearance rate of DA approaches a constant, $V_{\max }$ (i.e., zero-order kinetics). The values of $V_{\max }$ obtained using this method were not different from those obtained by the data simulations and, furthermore, demonstrated regional heterogeneity (data not shown).

\section{Frequency dependence of dopamine during pulse trains}

Steady-state $[\mathrm{DA}]_{\mathrm{o}}$ was compared in ventromedial versus dorsolateral regions of both the caudate and the putamen during pulse trains, over a range of frequencies $(2-20 \mathrm{~Hz})$ at which DA neurons may fire action potentials in situ (Grace and Bunney, 1983, 1984a,b; Schultz et al., 1983; Schultz, 1984, 1986). These data have been reported in part previously for the putamen (Cragg et al., 2000). As for the putamen, evoked $[\mathrm{DA}]_{\mathrm{o}}$ in the caudate nucleus peaked initially $(t \approx 0.5 \mathrm{sec})$ after the start of the stimulus (Fig. $3 a, b)$ to a concentration resembling that observed after a single pulse (Fig. 1). Subsequently, [DA] oither declined, remained constant at, or increased to an approximately steady-state concentration (at $t=2-3 \mathrm{sec}$ ) as a function both of the frequency of stimulation (Fig. 3a-c) (two-way ANOVA; $p<0.001 ; n=$ $4-10)$ and of the region $(p<0.001)$. In the ventromedial, limbicassociated caudate, each increase in the stimulation frequency increased $[\mathrm{DA}]_{\mathrm{o}}$ at steady-state times (compared with previous frequency) (e.g., Newman-Keuls multiple comparison $t$ tests; $p<$ 0.01 for $20 \mathrm{~Hz}$ vs 10 or $5 \mathrm{~Hz}$ ) with a facilitative (nonlinear) relationship, as in the ventromedial putamen (Fig. $3 c$ ). In the dorsolateral caudate, each increase in the stimulation frequency increased the steady-state $[\mathrm{DA}]_{\mathrm{o}}$ (compared with the previous frequency) up to $10 \mathrm{~Hz}$ (e.g., Newman-Keuls multiple comparison $t$ tests; $p<0.05$ for $2 \mathrm{~Hz}$ vs 10 or $20 \mathrm{~Hz}$ ): at $20 \mathrm{~Hz}$, no significant increase in $[\mathrm{DA}]_{\mathrm{o}}$ compared with $10 \mathrm{~Hz}$ was observed, as in the dorsolateral putamen (Fig. 3c).

Consistent with the regional differences in $[\mathrm{DA}]_{\mathrm{o}}$ observed after a single pulse, net $[\mathrm{DA}]_{\mathrm{o}}$ at low frequencies $(<10 \mathrm{~Hz})$ was significantly greater (approximately twofold) in the dorsolateral than in the ventromedial caudate ( $t$ tests; $p<0.01 ; n=4-5$ ). However, at higher frequencies, steady-state $[\mathrm{DA}]_{\mathrm{o}}$ in the ventromedial caudate becomes equal to $(10 \mathrm{~Hz})$ and eventually significantly greater than $(20 \mathrm{~Hz}$; more than twofold $)[\mathrm{DA}]_{\mathrm{o}}$ in the dorsolateral regions (Fig. $3 c)(p<0.01 ; n=6-10)$. An identical effect has been described previously for the putamen (Cragg et al., 2000), as illustrated for the comparison in Figure $3 c$.

Comparison of net, steady-state $[\mathrm{DA}]_{\mathrm{o}}$ in the caudate with the putamen at paired coordinates indicates no significant difference between the two nuclei (two-way ANOVAs for frequency and nucleus; $p<0.001$ and $p>0.05$, respectively) at either of the two coordinates.

\section{Recovery from presynaptic depression}

To characterize further the presynaptic properties of DA neurons innervating the striatal region most vulnerable to parkinsonian degeneration (i.e., the dorsolateral putamen), we evaluated and compared the recovery of the releasability of DA after presynaptic depression at the dorsolateral loci of the putamen and the caudate. At a given dorsolateral site in both the putamen and the caudate nuclei in each of four different animals, paired pulses of 

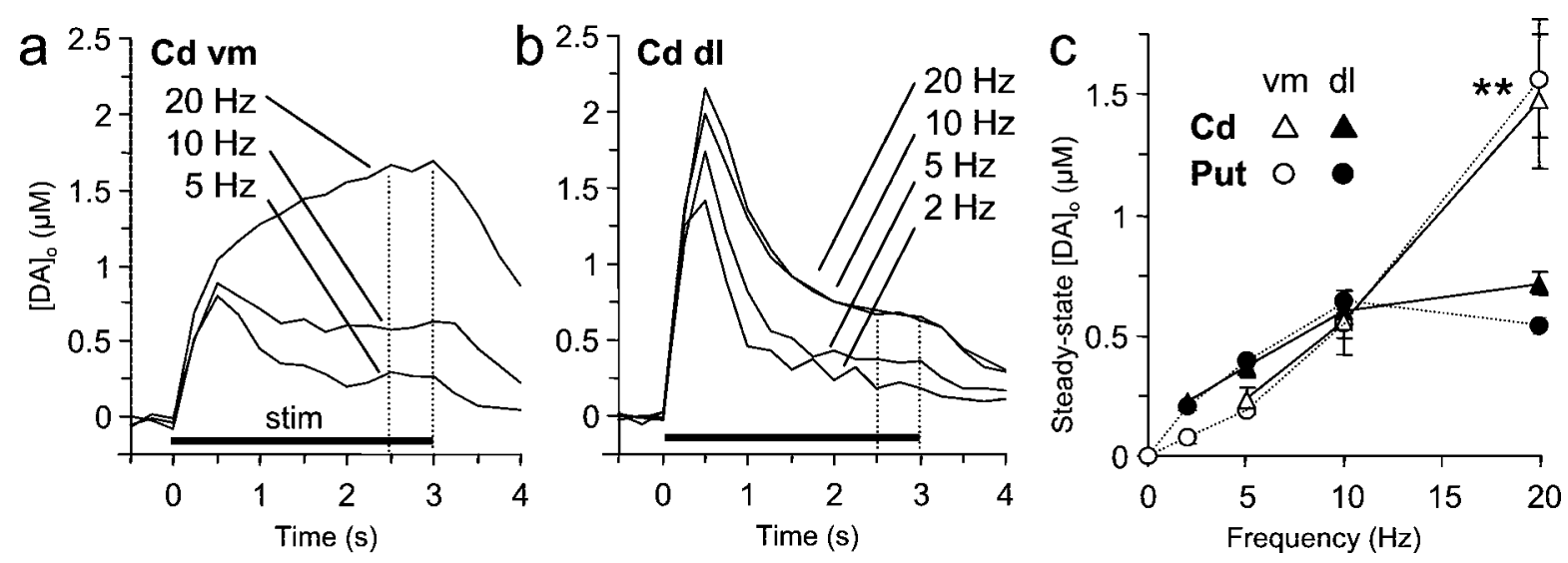

Figure 3. Frequency sensitivity of $[\mathrm{DA}]_{\mathrm{o}}$ during pulse trains. $a, b,[\mathrm{DA}]_{\mathrm{o}}$ versus time during 3 sec stimulation trains (stim, solid bar) over a range of frequencies $(2-20 \mathrm{~Hz})$ in the $\mathrm{vm}(a)$ and $\mathrm{dl}(b)$ caudate nucleus, $3<n<10$. SEMs are excluded for clarity. The steady-state [DA] , between dotted lines, varies differently with the frequency in each region. $c$, Steady-state $[\mathrm{DA}]_{\mathrm{o}}$ versus frequency in ventromedial (open symbols) and dorsolateral (filled symbols) regions of both the caudate (triangles) and, for comparison, putamen (circles). [DA $]_{\mathrm{o}}$ is a function of the frequency of stimulation (two-way ANOVA; $p<0.001)$ and subregion $(p<0.01)$. As in the putamen (dotted lines), in the dorsolateral caudate each increase in frequency up to $10 \mathrm{~Hz}$ increased $[\mathrm{DA}]_{\mathrm{o}}$ ( post hoc $t$ tests; $p<0.001-0.05 ; n=5-8$ ); in the ventromedial caudate, $[\mathrm{DA}]_{\mathrm{o}}$ increased supralinearly with the frequency $(p<$ $0.01-0.05 ; n=4-10)$. [DA $]_{\mathrm{o}}$ in the ventromedial regions significantly exceeded that in the dorsolateral regions at frequencies of $>10 \mathrm{~Hz}(20 \mathrm{~Hz} ; * * p<$ 0.01). There was no significant difference between the caudate and the putamen (two-way ANOVA). Data are means \pm SEM.

varying interpulse intervals (50 msec to $40 \mathrm{sec})$ were administered repeatedly and in random order, $5 \mathrm{~min}$ apart (Fig. $4 a$ ). The recordings sites were typical for each nucleus: Mean peak [DA] evoked by a single pulse was $2.08 \pm 0.03 \mu \mathrm{M}$ in the putamen, which more importantly was consistently greater than evoked [DA] $]_{\mathrm{o}}$ in the caudate $(1.64 \pm 0.23 \mu \mathrm{M} ; p<0.05 ; n=4)$. In both nuclei, a strong depression of release was observed at the second, paired pulse, which was inversely related to the interpulse interval (Fig. $4 a, b$ ). Full recovery of [DA] occurs only after $\sim 30 \mathrm{sec}$ (Fig. $4 a, b)$. The relationships between the paired-pulse ratio of [DA] [pulse $2(\mathrm{P} 2) /$ pulse $1(\mathrm{P} 1)$ ] and interpulse interval in both the caudate and the putamen could be fitted well with double exponentials $\left(R^{2}>0.99\right)$, as described previously for rodent striata (Kennedy et al., 1992; Abeliovich et al., 2000). The time constants derived from both fast and slow components were: caudate, 2.7 and $9.4 \mathrm{sec}$; putamen, 2.8 and $7.7 \mathrm{sec}$, shorter than those described in rodents. Although a two-way ANOVA (for time and region) indicates significant variation in $[\mathrm{DA}]_{\mathrm{o}}$ attributable to interpulse interval $(p<0.001)$, there is no significant difference in relative recovery between the caudate and the putamen $(n=4)$, despite the difference in absolute $[\mathrm{DA}]_{\mathrm{o}}$.

\section{DISCUSSION}

These data indicate region-specific heterogeneity in the dynamic regulation of $[\mathrm{DA}]_{\mathrm{o}}$ throughout the dorsal striatum of a nonhuman primate. Different functional domains are defined by corresponding differences in DA dynamics. Within a given functional domain, the anatomically segregated putamen and caudate nuclei nonetheless share similar DA dynamics.

\section{Single-pulse evoked dopamine and striatal domain}

$[\mathrm{DA}]_{\mathrm{o}}$ evoked locally by a single pulse was a function of the vm-dl coordinate in the caudate nucleus, as seen previously in the putamen (Cragg et al., 2000). From the three-site analysis of $[\mathrm{DA}]_{\mathrm{o}}\left(\right.$ and $[\mathrm{DA}]_{\mathrm{p}}$ ) within each nucleus, a marked gradient in DA availability is apparent (Fig. 5): evoked $[\mathrm{DA}]_{\mathrm{o}}$ increases from the ventromedial striatum through the central striatum to the DLS by twofold (caudate) to threefold (putamen).

Notably, intranucleus variation in $[\mathrm{DA}]_{\mathrm{o}}$ reflected the func- tional domain. For example, within the caudate nucleus, evoked $[\mathrm{DA}]_{\mathrm{o}}$ was lower in the ventromedial compared with the central sites, yet it was similar in the central and the dorsolateral sites: this heterogeneity parallels the segregation of these three loci into primarily two functional domains, the ventromedial/limbic $\mathrm{Cd}$ (vm Cd) and the central/associative (mid and $\mathrm{dl} \mathrm{Cd}$ ) (Haber et al., 2000). Interestingly, this finding is mirrored in basal [DA] seen within the caudate nucleus in rhesus monkeys (Bradberry et al., 2000). In contrast, in the putamen the significant difference in evoked $[\mathrm{DA}]_{\mathrm{o}}$ between each of the three loci in turn parallels the division into three functional domains, including the dorsolateral/motor Put (dl Put). Moreover, mean evoked [DA] within each functional domain was common to the putamen and the caudate. In other words, functional domains, which span anatomical segregation into the caudate and the putamen, can be delineated by DA availability.

These data suggest that functions assigned to a striatal subregion are more accurately described by mediolateral coordinates than by the nucleus. In particular, mesostriatal features assigned preferentially to the putamen and not the caudate may reside in dorsolateral projections (e.g., onset of parkinsonian degeneration), whereas features assigned preferentially to the caudate may result from a greater component of central/associative functions. The greatest $[\mathrm{DA}]_{\mathrm{o}}$ is evoked in the dorsolateral putamen, the only motor domain sampled, and notably, the region most susceptible to parkinsonian degeneration. Greater apparent DA availability/turnover in dorsolateral regions may, in turn, generate a greater accumulation of potentially toxic DA metabolites. Given the concordance between the degree of degeneration associated with each region in PD (Kish et al., 1988; Antonini et al., 1995) and DA availability, our observations indirectly support DA autotoxicity as a contributing factor in PD (for review, see Jenner and Olanow, 1996; Olanow and Tatton, 1999).

\section{Dopamine uptake and striatal domain}

The DAT was the dominant uptake mechanism governing [DA] and lifetime in the caudate, as observed in the putamen (Cragg et al., 2000). Like $[\mathrm{DA}]_{\mathrm{o}}$ and $[\mathrm{DA}]_{\mathrm{p}}$, uptake $V_{\max }$ varied in a region- 


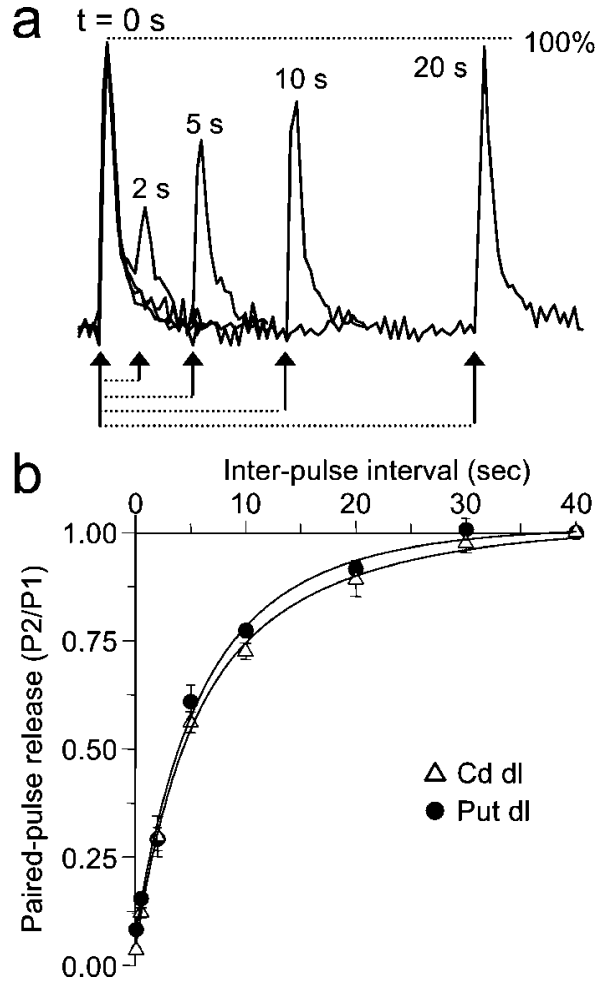

Figure 4. Recovery from presynaptic depression. $a$, A typical series for $[\mathrm{DA}]_{\mathrm{o}}$ versus time after paired stimulus pulses (arrows) delivered at interpulse intervals ranging from 2 to $20 \mathrm{sec}$ (dotted lines), recorded at a single site in the dorsolateral caudate. Plots are standardized to $100 \%$ of the release by the first pulse. Release is restored only after at least $20 \mathrm{sec}$. $b$, Mean $[\mathrm{DA}]_{\mathrm{o}}$ released by the second, paired pulse as a fraction of the first $(P 2 / P 1)$ versus the interpulse interval for the dorsolateral caudate (triangles) and the putamen (circles). Curve fits (solid lines) are double exponentials of the form $y=y_{0}+a\left(1-e^{-\mathrm{bx}}\right)+a\left(1-e^{-\mathrm{cx}}\right)$, where $y_{0}+$ $2 \times a=1$. Time constants of fast and slow components of illustrated fits are, respectively: Cd, 2.7 and $9.4 \mathrm{sec}$; Put, 2.8 and $7.7 \mathrm{sec}$. The two-way ANOVA indicates variation attributable to time $(p<0.001)$ but not region $(n=4)$.

specific manner that paralleled the segregation of the caudate and the putamen into, respectively, two versus three functional domains: $V_{\max }$ in dorsolateral locations was greater than that in ventromedial locations by $20 \%$ in the caudate and $50 \%$ in the putamen.

Within each functional domain, the mean $V_{\max }$ was similar in the caudate and the putamen. $V_{\max }$ was greatest in the dorsolateral putamen, the only motor domain sampled, and exceeded $V_{\max }$ in the dorsolateral caudate by $20 \%$. Thus, uptake, as for release, reflects the functional striatal domain, as defined by corticostriatal connectivity, primarily independently of anatomical segregation into the caudate versus the putamen.

Previous findings from techniques with less-defined spatial resolution show that overall DAT protein levels or ligand-binding density, $B_{\max }\left(\left[{ }^{125} \mathrm{I}\right]\right.$ altropane, $\left[{ }^{3} \mathrm{H}\right]$ mazindol, $\left[{ }^{3} \mathrm{H}\right] \mathrm{CFT}$, and $\left[{ }^{125}\right.$ I]RTI-55), in primate, including human, striatum are highest in the putamen (Donnan et al., 1991; Kaufman and Madras, 1992; Miller et al., 1997; Madras et al., 1998). These data can now be reinterpreted as a specific consequence of the greater motor component of the putamen compared with the caudate, and its associated greater $V_{\text {max }}$. Moreover, the regional heterogeneity in uptake will be an additional contributing factor in neurodegeneration; it explains the greater accumulation and regional neuro-

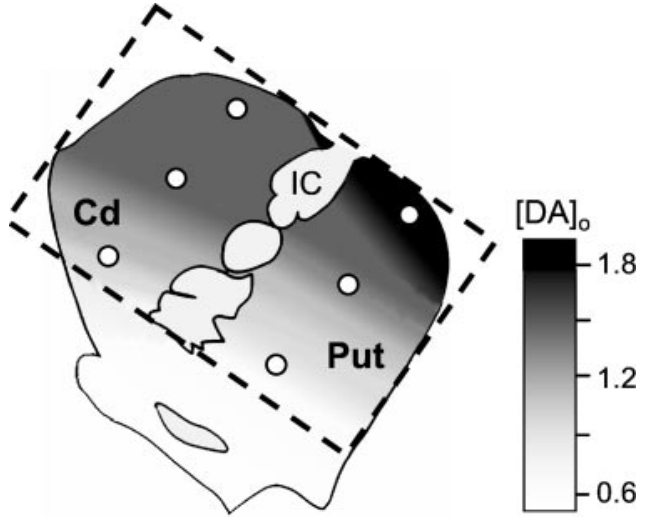

Figure 5. Summary of regional availability of DA. The gradient fill within the dorsal striatum enclosed by the dashed lines illustrates the relative regional availability of DA as determined by mean $[\mathrm{DA}]_{\mathrm{o}}$ evoked by a single pulse in the striatum, here indicated by a key, in micrometers. Representative recording locations along the $\mathrm{vm}-\mathrm{dl}$ axes used to define this gradient in both the $\mathrm{Cd}$ and the Put are indicated (circles). Regional differences in DA availability obey a vm-dl organization that spans the two nuclei. This territorial delineation parallels the known functional domains of the striatum defined by corticostriatal connectivity (for review, see Haber and McFarland, 1999; Haber et al., 2000). IC, Internal capsule.

toxicity of the MPTP metabolite and DAT substrate, 1-methyl4-phenylpyridinium (Elsworth et al., 1987; Moratalla et al., 1992), and may be a component of regional methamphetamine-induced toxicity (Harvey et al., 2000).

However, the distribution of DAT activity is inversely correlated with the effect of the DAT antagonist cocaine. Paradoxically, cocaine preferentially elevates $[\mathrm{DA}]_{\mathrm{o}}$ in limbic rather than motor-associated striata (Carboni et al., 1989; Cass et al., 1992; Kuczenski and Segal, 1992; Bradberry et al., 2000). The competitive antagonistic action of cocaine will be differently apparent when the DAT is differently saturated by endogenous DA. Wu et al. (2001) have suggested that lower rates for both dopamine release and uptake together underlie the preferential increase in $[\mathrm{DA}]_{\mathrm{o}}$ in the nucleus accumbens rather than the caudatoputamen of rats after the systemic injection of cocaine. According to this hypothesis, the greater action of cocaine in the ventromedial striatum rather than in the DLS documented in the nonhuman primate (Bradberry et al., 2000) could also be explained by our findings that both $[\mathrm{DA}]_{\mathrm{p}}$ and $V_{\max }$ are lowest in limbic-associated regions.

The positive correlations observed between $[\mathrm{DA}]_{\mathrm{p}}$ and $V_{\max }$ in both the caudate and the putamen, together with the regional variation in DA content (Cragg et al., 2000), suggest that the largest and fastest dopamine transients at dorsolateral coordinates result primarily from the densest dopaminergic innervation (Bjorklund and Lindvall, 1984). However, the faster $V_{\max }$ is not necessarily wholly attributable to fiber packing density, because dorsolaterally projecting mesostriatal DA neurons have the greatest DAT expression levels (Shimada et al., 1992; Blanchard et al., 1994; Hurd et al., 1994; Sanghera et al., 1994; Haber et al., 1995). Moreover, a dissociation is apparent between the parameters $[\mathrm{DA}]_{\mathrm{p}}$ and $V_{\max }$, where $[\mathrm{DA}]_{\mathrm{p}}$ tends toward zero before $V_{\max }$. Unless there is increased DAT density per releasing bouton with the ventromedial coordinate [a hypothesis contradictory to both expression studies (above) and ultrastructural findings in rodents (Nirenberg et al., 1997; Sesack et al., 1998)], this dissociation suggests that $[\mathrm{DA}]_{\mathrm{p}}$ is governed by factors beyond packing density. Other differences between DA neurons [e.g., membrane 
ionic conductances (for review, see Meir et al., 1999; Wolfart et al., 2001; Liss et al., 2001) or calcium-buffering properties (Gerfen et al., 1987; Haber et al., 1995)] may generate regional variation in release probability.

\section{Frequency sensitivity}

Net $[\mathrm{DA}]_{\mathrm{o}}$ during pulse trains reflects the release per pulse $\left([\mathrm{DA}]_{\mathrm{p}}\right)$ minus the reuptake (Wightman et al., 1988; Wightman and Zimmerman, 1990; Limberger et al., 1991; Kawagoe et al., 1992). At frequencies observed in vivo (e.g., 1-20 Hz) (Bunney et al., 1973; Grace and Bunney, 1983, 1984a; Schultz et al., 1983), the frequency sensitivity of $[\mathrm{DA}]_{\mathrm{o}}$ varied significantly within both nuclei. There was a supralinear effect of the frequency in the ventromedial caudate but a frequency insensitivity in the dorsolateral regions of $>10 \mathrm{~Hz}$. These two effects strongly resemble those seen previously within the putamen (cf. Cragg et al., 2000). We have already demonstrated that because of weaker uptake and presynaptic autoinhibition of release by $\mathrm{D}_{2}$-like receptors, levels of evoked $[\mathrm{DA}]_{\mathrm{o}}$ in the ventromedial putamen can exceed those dorsolaterally during pulse trains despite the lower levels of DA available for release (Cragg et al., 2000): it is possible that a similar scenario operates within the caudate nucleus. The similarity in net $[\mathrm{DA}]_{\mathrm{o}}$ between related domains of the caudate versus the putamen could have been predicted given the approximately similar $[\mathrm{DA}]_{\mathrm{p}}$ and $V_{\max }$ of uptake. By related mechanisms, similar net $[\mathrm{DA}]_{\mathrm{o}}$ could be generated in dorsolateral regions of the caudate and the putamen (central vs dorsolateral territories), despite the greater release and uptake during any single release transient. These differences in homeostatic control of [DA] between domains in both the putamen and the caudate are consistent with a different temporal precision of DA signaling (low vs high) that has been proposed to be appropriate for limbic- versus motor-associated functions, respectively (Horvitz, 2000).

\section{Recovery from presynaptic depression}

After a single stimulus, DA release exhibited a fast depression. Slow recovery was described by a double exponential function, which (in rodents) results from, among others (Kennedy et al., 1992), DA autoreceptors (Kennedy et al., 1992; Benoit-Marand et al., 2001), $\left[\mathrm{Ca}^{2+}\right], \alpha$-synuclein (Abeliovich et al., 2000), and by analogy to other neurotransmitters, rates of vesicle refill/redock/ priming (for review, see Thomson, 2000). Recovery time constants are faster than those reported previously in rodents; however, it is unclear whether this discrepancy reflects experimental or important species differences. According to these time constants, the net constraints on presynaptic recovery in the caudate and the putamen were equivalent. Therefore, greater initial DA availability and reuptake do not confer greater apparent presynaptic re-releasability.

\section{Conclusions}

We have described distinct differences within the primate dorsal striatum in DA dynamics, in particular, in availability for release, avidity of uptake, and their interactions. Consequently, striatal functional domains are differentiated by this dynamic availability of DA, independently of caudate/putamen anatomical segregation. Caudate/putamen differences (e.g., susceptibility to degeneration) are probably attributable to their mediolateral organization and consequent limbic versus motor dopaminergic components.

These data indicate how DA may be used in different manners, quantitatively and qualitatively, for different functions within the striatum. Interestingly, DA behavior may be necessarily correlated with properties of sites of action: for example, the density of striatonigral projection neurons varies in parallel along the same axis (ventromedial $>$ dorsolateral) (Haber et al., 2000). The heterogeneity in the dynamic behavior of DA surpasses that seen in the rodent caudatoputamen (Cragg et al., 2000). This unparalleled heterogeneity may reflect the increased functional specialization of the primate brain, in particular the greater repertoire of functions modulated by DA, including movements and affect. Furthermore, these data may underlie the regional specificity of the primate striatum to psychostimulant drugs and neurodegenerative disease.

\section{REFERENCES}

Abeliovich A, Schmitz Y, Farinas I, Choi-Lundberg D, Ho WH, Castillo PE, Shinsky N, Verdugo JM, Armanini M, Ryan A, Hynes M, Phillips H, Sulzer D, Rosenthal A (2000) Mice lacking $\alpha$-synuclein display functional deficits in the nigrostriatal dopamine system. Neuron 25:239-252.

Alexander GE, DeLong MR (1985) Microstimulation of the primate neostriatum. II. Somatotropic organization of striatal microexcitable zones and their relation to neuronal response properties. J Neurophysiol 53:1417-1430.

Antonini A, Vontobel P, Psylla M, Gunther I, Maguire PR, Missimer J, Leenders KL (1995) Complementary positron emission tomographic studies of the striatal dopaminergic system in Parkinson's disease. Arch Neurol 52:1183-1190.

Benoit-Marand M, Borrelli E, Gonon F (2001) Inhibition of dopamine release via presynaptic $D_{2}$ receptors: time course and functional characteristics in vivo. J Neurosci 21:9134-9141.

Bjorklund A, Lindvall O (1984) Dopamine-containing systems in the CNS. In: Handbook of chemical neuroanatomy (Bjorklund A, Hokfelt T, eds), pp 55-122. New York: Elsevier.

Blanchard V, Raisman-Vozari R, Vyas S, Michel PP, Javoy-Agid F, Uhl G, Agid Y (1994) Differential expression of tyrosine hydroxylase and membrane dopamine transporter genes in subpopulations of dopaminergic neurons of the rat mesencephalon. Mol Brain Res 22:29-40.

Bradberry CW, Barrett-Larimore RL, Jatlow P, Rubino SR (2000) Impact of self-administered cocaine and cocaine cues on extracellular dopamine in mesolimbic and sensorimotor striatum in rhesus monkeys. J Neurosci 20:3874-3883.

Bunney BS, Walters JR, Roth RH, Aghajanian GK (1973) Dopaminergic neurons: effect of antipsychotic drugs and amphetamine on single cell activity. J Pharmacol Exp Ther 185:560-571.

Carboni E, Imperato A, Perezzani L, Di Chiara G (1989) Amphetamine, cocaine, phencyclidine and nomifensine increase extracellular dopamine concentrations preferentially in the nucleus accumbens of freely moving rats. Neuroscience 28:653-661.

Cass WA, Gerhardt GA, Mayfield RD, Curella P, Zahniser NR (1992) Differences in dopamine clearance and diffusion in rat striatum and nucleus accumbens following systemic cocaine administration. J Neurochem 59:259-266.

Cragg SJ, Greenfield SA (1997) Differential autoreceptor control of somatodendritic and axon terminal dopamine release in substantia nigra, ventral tegmental area, and striatum. J Neurosci 17:5738-5746.

Cragg SJ, Hille CJ, Greenfield SA (2000) Dopamine release and uptake dynamics within nonhuman primate striatum in vitro. J Neurosci 20:8209-8217.

Crutcher MD, DeLong MR (1984) Single cell studies of the primate putamen. I. Functional organisation. Exp Brain Res 53:233-243.

Donnan GA, Kaczmarczyk SJ, Paxinos G, Chilco PJ, Kalnins RM, Woodhouse DG, Mendelsohn FA (1991) Distribution of catecholamine uptake sites in human brain as determined by quantitative $\left[{ }^{3} \mathrm{H}\right]$ mazindol autoradiography. J Comp Neurol 304:419-434.

Elsworth JD, Deutch AY, Redmond DE, Sladek JR, Roth RH (1987) Effects of 1-methyl-4-phenyl-1,2,3,6-tetrahydropyridine (MPTP) on catecholamines and metabolites in primate brain and CSF. Brain Res 415:293-299.

Gerfen CR, Baimbridge KG, Thibault J (1987) The neostriatal mosaic. III. Biochemical and developmental dissociation of patch-matrix mesostriatal systems. J Neurosci 7:3935-3944.

Gimenez-Amaya JM, McFarland NR, las-Heras S, Haber SN (1995) Organization of thalamic projections to the ventral striatum in the primate. J Comp Neurol 354:127-149.

Giros B, Jaber M, Jones SR, Wightman RM, Caron MG (1996) Hyperlocomotion and indifference to cocaine and amphetamine in mice lacking the dopamine transporter. Nature 379:606-612.

Grace AA, Bunney BS (1983) Intracellular and extracellular electrophysiology of nigral dopaminergic neurons. I. Identification and characterisation. Neuroscience 10:301-315.

Grace AA, Bunney BS (1984a) The control of firing pattern in nigral dopamine neurons: single spike firing. J Neurosci 4:2866-2876. 
Grace AA, Bunney BS (1984b) The control of firing pattern in nigral dopamine neurons: burst firing. J Neurosci 4:2877-2890.

Haber SN, McFarland NR (1999) The concept of the ventral striatum in nonhuman primates. Ann NY Acad Sci 877:43-48.

Haber SN, Ryoo H, Cox C, Lu W (1995) Subsets of midbrain dopaminergic neurons in monkeys are distinguished by different levels of mRNA for the dopamine transporter: comparison with the mRNA for the D2 receptor, tyrosine hydroxylase and calbindin immunoreactivity. J Comp Neurol 362:400-410.

Haber SN, Fudge JL, McFarland NR (2000) Striatonigrostriatal pathways in primates form an ascending spiral from the shell to the dorsolateral striatum. J Neurosci 20:2369-2382.

Harvey DC, Lacan G, Melegan WP (2000) Regional heterogeneity of dopaminergic deficits in vervet monkey striatum and substantia nigra after methamphetamine exposure. Exp Brain Res 133:349-358.

Hazrati LN, Parent A (1992) The striatopallidal projection displays a high degree of anatomical specificity in the primate. Brain Res 592:213-227.

Hornykiewicz O (1966) Dopamine (3-hydroxytyramine) and brain function. Pharmacol Rev 18:925-964.

Horvitz JC (2000) Mesolimbocortical and nigrostriatal dopamine responses to salient non-reward events. Neuroscience 96:651-656.

Hurd YL, Pristupa ZB, Herman MM, Niznik HB, Kleinman JE (1994) The DA transporter and DA D2 receptor mRNAs are differentially expressed in limbic- and motor-related subpopulations of human mesencephalic neurons. Neuroscience 63:357-362.

Jenner P, Olanow CW (1996) Oxidative stress and the pathogenesis of Parkinson's disease. Neurology 47:S161-S170.

Jones SR, Garris PA, Kilts CD, Wightman RM (1995) Comparison of dopamine uptake in the basolateral amygdaloid nucleus, caudateputamen and nucleus accumbens of the rat. J Neurochem 64:2581-2589.

Kaufman MJ, Madras BK (1991) Severe depletion of cocaine recognition sites associated with the dopamine transporter in Parkinson'sdiseased striatum. Synapse 9:43-49.

Kaufman MJ, Madras BK (1992) Distribution of cocaine recognition sites in monkey brain. II. Ex vivo autoradiography with $\left[{ }^{3} \mathrm{H}\right] \mathrm{CFT}$ and $\left[{ }^{125}\right.$ I]RTI-55. Synapse 12:99-111.

Kawagoe KT, Garris PA, Wiedemann DJ, Wightman RM (1992) Regulation of transient dopamine concentration gradients in the microenvironment surrounding nerve terminals in the rat striatum. Neuroscience 51:55-64.

Kennedy RT, Jones SR, Wightman RM (1992) Dynamic observation of dopamine autoreceptor effects in rat striatal slices. J Neurochem 59:449-455.

Kish SJ, Shannak K, Hornykiewicz O (1988) Uneven pattern of dopamine loss in the striatum of patients with idiopathic Parkinson's disease: pathophysiologic and clinical implications N Engl J Med 318:876-880.

Kuczenski R, Segal DS (1992) Differential effects of amphetamine and dopamine uptake blockers (cocaine, nomifensine) on caudate and accumbens dialysate dopamine and 3-methoxytyramine. J Pharmacol Exp Ther 262:1085-1094.

Kunzle H (1975) Bilateral projections from precentral motor cortex to the putamen and other parts of the basal ganglia: an autoradiographic study in Macaca fascicularis. Brain Res 88:195-209.

Kunzle H (1977) Projections from the primary somatosensory cortex to basal ganglia and thalamus in the monkey. Exp Brain Res 30:481-492.

Limberger N, Trout SJ, Kruk ZL, Starke K (1991) "Real-time" measurement of endogenous DA release during short trains of pulses in slices of rat neostriatum and nucleus accumbens: role of autoinhibition. Naunyn Schmiedebergs Arch Pharmacol 344:623-629.

Liss B, Franz O, Sewing S, Bruns R, Neuhoff H, Roeper J (2001) Tuning pacemaker frequency of individual dopaminergic neurons by $\mathrm{Kv} 4.3 \mathrm{~L}$ and KChip3.1 transcription. EMBO J 20:5715-5724.

Lynd-Balta E, Haber SN (1994a) Primate striatonigral projections: a comparison of the sensorimotor-related striatum and the ventral striatum. J Comp Neurol 345:562-578.

Lynd-Balta E, Haber SN (1994b) The organization of midbrain projections to the striatum in the primate: sensorimotor-related striatum versus ventral striatum. Neuroscience 59:625-640.

Madras BK, Gracz LM, Fahey MA, Elmaleh D, Meltzer PC, Liang AY, Stopa EG, Babich J, Fischman AJ (1998) Altropane, a SPECT or PET imaging probe for dopamine neurons. III. Human dopamine transporter in postmortem normal and Parkinson's diseased brain. Synapse 29:116-127.

Maloteaux JM, Vanisberg MA, Laterre C, Javoy-Agid F, Agid Y, Laduron PM (1988) $\left[{ }^{3} \mathrm{H}\right] \mathrm{GBR} 12935$ binding to dopamine uptake sites: subcellular localization and reduction in Parkinson's disease and progressive supranuclear palsy. Eur J Pharmacol 156:331-340.

McFarland NR, Haber SN (2000) Convergent inputs from thalamic motor nuclei and frontal cortical areas to the dorsal striatum in the primate. J Neurosci 20:3798-3813.
Meir A, Ginsburg S, Butkevich A, Kachalsky SG, Kaiserman I, Ahdut R, Demirgoren S, Rahamimoff R (1999) Ion channels in presynaptic nerve terminals and control of transmitter release. Physiol Rev 79:1019-1088.

Miller GW, Staley JK, Heilman CJ, Perez JT, Mash DC, Rye DB, Levey AI (1997) Immunochemical analysis of dopamine transporter protein in Parkinson's disease. Ann Neurol 41:530-539.

Moratalla R, Quinn B, DeLanney LE, Irwin I, Langston JW, Graybiel AM (1992) Differential vulnerability of primate caudate-putamen and striosome-matrix dopamine systems to the neurotoxic effects of 1-methyl-4-phenyl-1,2,3,6-tetrahydropyridine. Proc Natl Acad Sci USA 89.3859-3863.

Nirenberg MJ, Chan J, Pohorille A, Vaughan RA, Uhl GR, Kuhar MJ, Pickel VM (1997) The dopamine transporter: comparative ultrastructure of dopaminergic axons in limbic and motor compartments of the nucleus accumbens. J Neurosci 17:6899-6907.

Olanow CW, Tatton WG (1999) Etiology and pathogenesis of Parkinson's disease. Annu Rev Neurosci 22:123-144.

Parent A, Mackey A, De Bellefeuille L (1983) The subcortical afferents to caudate nucleus and putamen in primate: a fluorescence retrograde double labeling study. Neuroscience 10:1137-1150.

Rice ME, Cragg SJ, Greenfield SA (1997) Characteristics of electrically evoked somatodendritic dopamine release in substantia nigra and ventral tegmental area in vitro. J Neurophysiol 77:853-862.

Ross SB (1991) Synaptic concentration of dopamine in the mouse striatum in relationship to the kinetic properties of the dopamine receptors and uptake mechanism. J Neurochem 56:22-29.

Russchen FT, Bakst I, Amaral DG, Price JL (1985) The amygdalostriatal projections in the monkey: an anterograde tracing study. Brain Res 329:241-257.

Sanghera MK, Manaye KF, Liang C-L, Iacopino AM, Bannon MJ, German DC (1994) Low dopamine transporter mRNA levels in midbrain regions containing calbindin. NeuroReport 5:1641-1644.

Schoemaker H, Pimoule C, Arbilla S, Scatton B, Javoy-Agid F, Langer SZ (1985) Sodium dependent $\left[{ }^{3} \mathrm{H}\right]$ cocaine binding associated with dopamine uptake sites in the rat striatum and human putamen decrease after dopaminergic denervation and in Parkinson's disease. Naunyn Schmiedebergs Arch Pharmacol 329:227-235.

Schultz W (1984) Primate dopamine cell activity in relation to behavioural acts. Clin Neuropharmacol 7:48-49.

Schultz W (1986) Responses of midbrain dopamine neurons to behavioral trigger stimuli in the monkey. J Neurophysiol 56:1439-1461.

Schultz W, Ruffieux A, Aebischer P (1983) The activity of pars compacta neurons of the monkey substantia nigra in relation to motor activation. Exp Brain Res 51:377-387.

Seeman P, Niznik HB (1990) Dopamine receptors and transporters in Parkinson's disease and schizophrenia. FASEB J 4:2737-2744.

Selemon LD, Goldman-Rakic PS (1985) Longitudinal topography and interdigitation of corticostriatal projections in the rhesus monkey. J Neurosci 5:776-794.

Sesack SR, Hawrylak VA, Matus C, Guido MA, Levey AI (1998) Dopamine axon varicosities in the prelimbic division of the rat prefrontal cortex exhibit sparse immunoreactivity for the dopamine transporter. J Neurosci 18:2687-2708.

Shimada S, Kitayama S, Walther D, Uhl G (1992) Dopamine transporter mRNA: dense expression in ventral midbrain neurons. Mol Brain Res 13:359-362.

Smith Y, Parent A (1986) Differential connections of caudate nucleus and putamen in the squirrel monkey (Saimiri sciureus). Neuroscience 18:347-371.

Stephan H, Baron G, Schwerdtfeger WK (1980) The brain of the common marmoset (Callithrix jacchus): a stereotaxic atlas. New York: Springer.

Szabo J (1980) Organization of the ascending striatal afferents in monkeys. J Comp Neurol 189:307-321.

Thomson AM (2000) Molecular frequency filters at central synapses. Prog Neurobiol 62:159-196.

Wightman RM, Zimmerman JB (1990) Control of dopamine extracellular concentration in rat striatum by impulse flow and uptake. Brain Res Brain Res Rev 15:135-144.

Wightman RM, Amatore C, Engstrom RC, Hale PD, Kristensen EW, Kuhr WG, May LJ (1988) Real-time characterization of dopamine overflow and uptake in the rat striatum. Neuroscience 25:513-523.

Wolfart J, Neuhoff H, Franz O, Roeper J (2001) Differential expression of the small-conductance, calcium-activated potassium channel SK3 is critical for pacemaker control in dopaminergic midbrain neurons. J Neurosci 21:3443-3456.

Wu Q, Reith ME, Kuhar MJ, Carroll FI, Garris PA (2001) Preferential increases in nucleus accumbens dopamine after systemic cocaine administration are caused by unique characteristics of dopamine neurotransmission. J Neurosci 21:6338-6347. 